\title{
Investigating Iraqi EFL Learners' Performance in Utilizing the Speech Acts of Advice and Suggestion
}

\author{
Abbas Deygan Darweesh ${ }^{1} \&$ Nesaem Mehdi Al-Aadili ${ }^{1}$ \\ ${ }^{1}$ University of Babylon/ College of Education for Human Sciences/ Department of English \\ Correspondence: Abbas Deygan Darweesh, Department of English, College of Education for Human Sciences, \\ University of Babylon, Babylon, Iraq. E-mail: abbasdeygan@gmail.com; nasaem_rose_i@yahoo.com
}

Received: November 1, 2016

Accepted: May 22, 2017 Online Published: July 15, 2017

doi:10.5539/ijel.v7n4p179

URL: http://doi.org/10.5539/ijel.v7n4p179

\begin{abstract}
This study explores the pragmatic strategies of the English speech acts of "suggestion" and "advice" as used by Iraqi EFL university students. The data analyzed in this study were collected in the Dept. of English, College of Education, University of Babylon. The subjects encompass 50 Iraqi EFL undergraduate learners who are native speakers of Arabic. The gender of the subjects is taken into consideration during the execution of the speech acts in question. The instrument of the study is a discourse completion task (DCT) consisting of two questions. In responding to the questions, the participants are asked to pay heed to the social variable of status to see whether it affects the execution of the speech acts under study.
\end{abstract}

Keywords: speech acts, advice, suggestion, strategies, Iraqi EFL learners' performance

\section{Preliminaries}

Both advice and suggestion are speech acts used in daily communication to influence other people. They are milder than commands since the decision about what to do is in the hands of the hearer, but in practice they are tactful ways of giving commands or instructions, thus, they are regarded as face-threatening acts that need to be softened or mitigated. In EFL classrooms, the major aim is not only to teach students how to utilize speech acts but also how to interpret and comprehend them with respect to the strategies used to indicate each act in order to develop a pragmatic competence that is computed on the basis of the ability to understand the intended meaning. This competence covers both sociolinguistic and illocutionary aspects and since the uses of the strategies which realize speech acts vary across cultures, the focus is on social appropriateness because the addresser could have in mind a variety of intended meanings which are considered a barrier to successful communication. These barriers may be educational and sociocultural. The problem would become more pressing because illocutionary competence is not always directly grasped from its surface structure that is why learning the pragmatic rules(appropriateness and politeness rules) of other languages enables the learners to produce forms of language that are socially and culturally appropriate since the native language of the learners and the other languages are not similar. As such, the study proposes the following hypotheses as a point of departure : (1)the speech acts of advice and suggestion are similar in certain respects and different in others, (2) different pragmatic strategies and syntactic formulae are employed by Iraqi EFL learners to accomplish the speech acts in question, (3)direct strategies are more frequent than others in the performance of the subjects, and (4) female subjects are more cognizant of status in responding to the situations they are given than their male counterparts, and (5) female learners use more politeness markers than their male counterparts..

\section{The Concept of Speech Acts}

Much has been said about the concept and theory of speech acts and politeness Austin (1962), Searle (1969), Brown \& Levinson (1987), Bouwmeester (2010), and Thomas (1995)). Thus, this study touches briefly on the speech acts under scrutiny.

1). Both suggestion and advice belong to directives, which are acts in which the speaker's purpose is to get the hearer to commit himself to some future course of action (Searle, 1969, p. 7).

2). Both speech acts are performed to get the hearer take some kind of action. However, the action that is mentioned is directed to the hearer only in the case of advice, whereas in suggestion, it can include the speaker as well as in "Let's try that restaurant"; "Shall we go now?" (Nakagawa \& Nishimura, 1998, p. 48) 
3). In suggestion, the predicted act is performed either by the hearer or by the hearer and the speaker together, whereas in advice, the predicted act is performed by the hearer alone (Lakoff \& Ide, 2005, p. 218).

4). The main feature that distinguishes advice from suggestion is the fact that advice implies a future course of action which is in the sole interest of the hearer, while suggestion may imply benefits for both interlocutors (Martinez-Flor, 2003, p. 140).

5). Both speech acts are face-threatening acts and both of them are rarely given explicitly in English.

6). Advice has the possibility of strong negative connotation, while suggestion is less assertive and forceful than advice. It does not include a negative connotation and it may be tentative (Matsumura, 2001, p. 677).

7). Some synonyms for advice that do not apply for suggest include admonish, offer an opinion, encourage, caution and warn. Meanings unique to suggest include propose, move, submit and advance.

\section{Linguistic Realizations of Advice}

Thomson \& Martinet (2001, p. 250) mention that advice can be indicated through the use of different linguistic forms and expressions:

A. must, ought to and should can be used to express advice:

- You should grow your vegetables.

\section{B. You had better+bare infinitive}

- You'd better take off your wet shoes.

\section{If I were you I should/would.....}

- If I were you I would buy a car.

\section{I advise/would advise you+infinitive or I advise/would advise you+gerund}

- I (would) advise you to apply at once.

- I (would) advise applying at once.

E. Why don't you....?

- Why don't you learn to play your guitar?

- Why don't you take a holiday?

\section{F. It is time you+past tense}

- It is time you bought a new coat.

G. You may/might as well+infinitive. This construction can express very unemphatic advice

- You may as well ask him= It would do no harm to ask him.

\section{The Pragmatic Strategies of Expressing Advice}

Martinez-Flor (2003, p. 144) remarks that there are three types of strategies used to realize the speech act of advice. These strategies are: direct, conventionally indirect and non-conventionally indirect strategies.

The first type of strategies is classified into four different realizations: imperatives as in "Study", negative imperatives "Don't go out until late", declarative sentences with "should" or "ought to" as in "You should study more for that exam", and declarative sentences with performative verbs as in "I advise you to study more." In the latter case, the verb "advise" and the noun "advice" as in "My advice to you is...." are used (ibid.).

The second type of strategies, that is indirect conventionalized strategies, includes three linguistic realizations: conditional as in "If I were you, I would study", probability "It might be better for you to study hard", and specific interrogative formulae (ibid.). Nakagawa and Nishimura (1998, p. 48) present some of these formulae which signal advice. These expressions include the following: "How about..?", "what about..?", etc.

Matsumura (2001, p. 677) mentions that the difference between direct and indirect advice depends on the strength of the forms used to express advice. For example, forms as "You must", "You should", "You'd better" and imperatives would be categorized as direct advice. Other forms such as "You can/could", "You might want to" and "It may/would be a good idea to" could be categorized as indirect advice.

The third type of strategies, indirect non-conventionalized strategies, includes those hints in which the speaker's intentions are not made explicitly as in "You want to pass, don't you" (Martinez-Flor, 2003, p. 144).

The following table summarizes the various linguistic strategies used to express advice: 
Table 1. Advice linguistic strategies

\begin{tabular}{lll}
\hline Type & Strategy & Example \\
\hline \multirow{3}{*}{ Direct } & Imperative & Be careful \\
& Negative imperative & Don't worry \\
& Declarative & You should/ ought to/ must/ had better.... \\
& Performative & I advise you to...... \\
& & My advice is.... \\
\hline \multirow{3}{*}{$\begin{array}{l}\text { Indirect } \\
\text { conventionalized }\end{array}$} & Conditional & If I were you,...... \\
& Probability & It might be better for you.... \\
& Interrogative & Why don't you....? \\
\hline Indirect & Declarative & You can/ could/ might..... \\
non-conventionalized & Hints & You want to pass, don't you? \\
\hline
\end{tabular}

\section{Linguistic Realizations of Suggestion}

Thomson \& Martinet (2001, pp. 251-252) mention that suggestions can be realized through the use of different expressions and formulae as follows:

A. First person suggestions with let's

- Let's get the paint today, shall we?

B. First and second person suggestions through the use of the following expressions: why don't we/you+infinitive or why not+infinitive/expression of time or place:

- Why don't we meet and discuss it?

-Why not meet and discuss it?

- Where shall we meet? - Why not here? / Why not at the hotel?

C. First, second or third person suggestions with suggest or propose:

suggest (+possessive adjective)+gerund or suggest that+subject+present tense/should.(propose is used in exactly the same way but is slightly more formal than suggest).

- I suggest (your) selling it.

- We suggest that you should sell it.

- I propose that the secretary sends in/should send in a report.

Thus, Leech \& Svartvik (1996, p. 168) state that suggestions are either including the speaker or are denoted to the hearer only. Both can be realized through different realizations:

\section{A. Suggestions involving the speaker}

- I suggest we go to bed early, and make an early start tomorrow.

- How about a game of cards?

- What about having a drink?

- Let's go and eat.

\section{B. Suggestions denoted to the hearer}

- You can read these two chapters before tomorrow.

- You could be cleaning the office while I'm away.

- You might have a look at this book.

- Why don't you call at me tomorrow?

\section{The Pragmatic Strategies of Expressing Suggestion}

Suggestions can be expressed through the use of various strategies including direct strategies, indirect conventionalized strategies and indirect non-conventionalized strategies. Direct strategies are resorted to when the speaker clearly states what he suggests through recourse to a performative verb denoting suggestion as in "I suggest that you change the data of the exam", a noun of suggestion as in "My suggestion to you is to get into that" or imperatives and negative imperatives as in "Try using this computer" "Don't try to use this program" 
(Bardovi-Harlig \& Hartford, 1996, p. 180).

Koester $(2002$, p. 181) remarks that, in English, the use of a performative verb and a noun of suggestion to denote suggestion is not widely employed in everyday life since it is very direct. Also, he states that the use of imperatives is regarded as the most direct and impolite form of making a suggestion since it has the most literal pragmatic force.

Indirect conventionalized strategies are not as direct as the first type. They allow the hearer to understand the speaker's intentions behind the suggestion. They involve a greater variety of linguistic realizations such as the use of interrogative forms "Why don't you phone this person?", expressions of possibility or probability "You might leave this for tomorrow", suggestions performed by means of the verbs "should" and "need", and conditionals "If I were you, I would buy a new computer" (Koike, 1996, p. 264).

Indirect non-conventionalized strategies refer to those expressions in which the speaker's true intentions are not clearly stated, that is, there is no indicator of the suggestive force in the utterance, so the hearer has to infer that the speaker is actually making a suggestion. The use of different impersonal forms as in "It would be helpful if you could find his telephone number" has been regarded as a way of making indirect suggestions (Hinkel, 1994, pp. 71-72).

The coming next table summarizes the various linguistic strategies used to express suggestion:

Table 2. Suggestion linguistic strategies

\begin{tabular}{|c|c|c|}
\hline Type of Strategies & Strategy & Example \\
\hline \multirow[t]{4}{*}{ Direct } & Performative verb & I suggest that you..... \\
\hline & Noun of suggestion & My suggestion would be...... \\
\hline & Imperative & Try using...... \\
\hline & Negative imperative & Don't try to...... \\
\hline Indirect & Interrogative forms & Why don't you....? \\
\hline \multirow[t]{6}{*}{ Conventionalized } & & How about/what about......? \\
\hline & & Have you thought about....? \\
\hline & Let's & Let's play football \\
\hline & Possibility/probability & You can/you could.... \\
\hline & & You may/you might.... \\
\hline & Conditional & If I were you, I would.... \\
\hline Indirect & Impersonal & -One thing (that you can do) would be.... \\
\hline \multirow[t]{6}{*}{ Non-conventionalized } & & -There are a number of options that you.... \\
\hline & & -It would be helpful if you... \\
\hline & & -It might be better to.... \\
\hline & & -A good idea would be.... \\
\hline & & -It would be nice if.... \\
\hline & Hints & I've heard that... \\
\hline
\end{tabular}

\section{Model of Analysis}

The model of analysis developed by this study is based on what has been discussed in the previous sections, notably the pragmatic strategies and syntactic formulae used to realize each of the speech acts under examination. The model is basically divided into three basic components: direct strategies, indirect conventionalized strategies, and indirect non-conventionalized strategies; each of which is realized by certain syntactic formulae. This is applicable to the model which addresses the speech act of advice and the model which addresses the speech act of suggestion. Figure (1) and (2) below will summarize this model: 


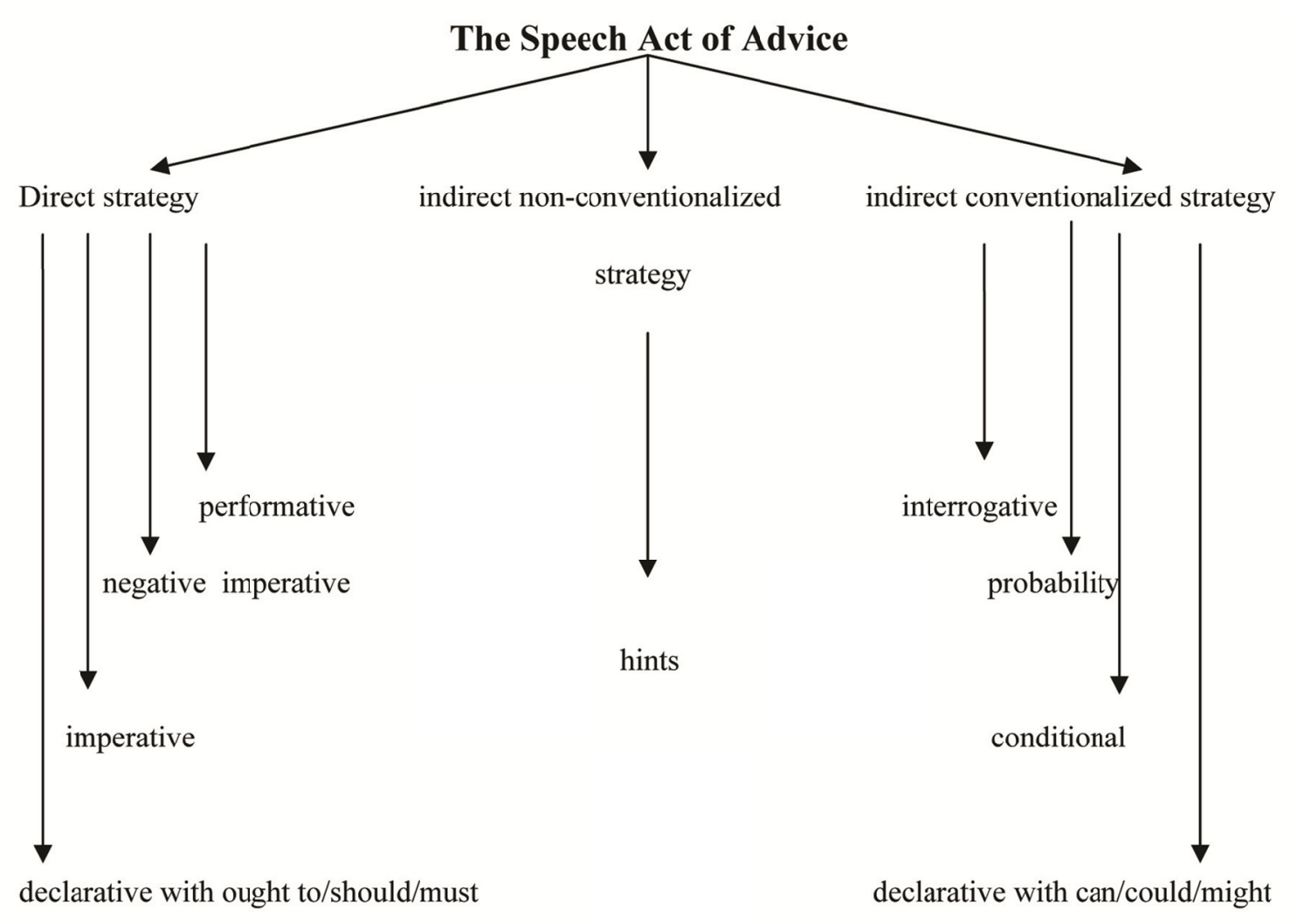

Figure 1. The pragmatic strategies and syntactic formulae that realize the speech act of advice

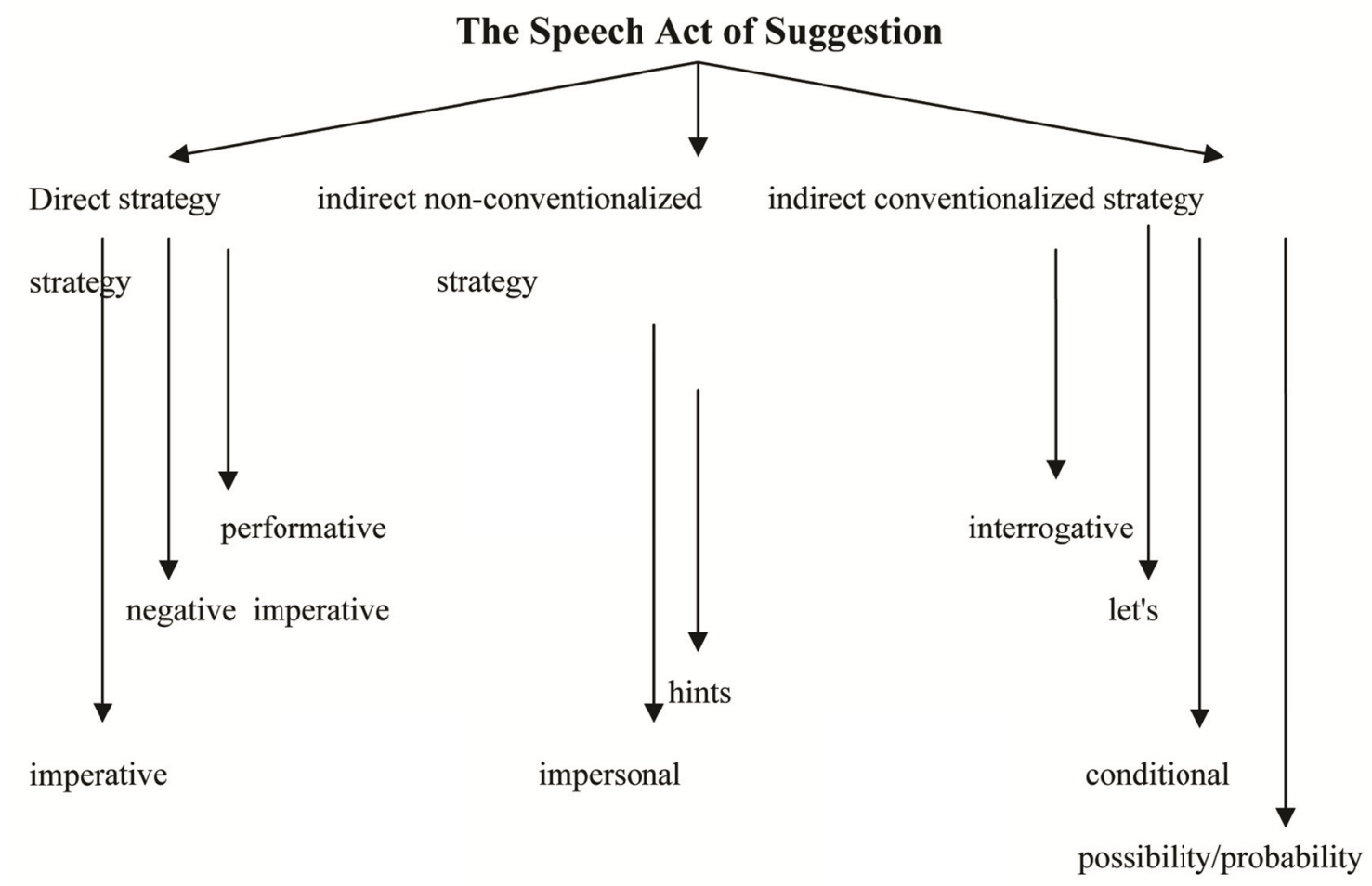

Figure 2. The pragmatic strategies and syntactic formulae that realize the speech act of suggestion 


\section{Results and Discussions}

After correcting students' responses to the test they are given, the following results have been reached at as far as the first question about advice situations is concerned:

\section{Situation (1):}

- $\quad 40$ students used the direct strategy with the following numbers and percentages: 19 students used the imperative to score (38\%), 21 students used the performative $(42 \%)$, and no student used the declarative construction with ought to/must/should. 10 students used the indirect conventionalized strategy via the following constructions: 6studentsused the declarative construction with" could and might" scoring (12\%) and 4 students made use of the interrogative one scoring $(8 \%)$. No student at all used the indirect non-conventionalized strategy represented by the utilization of hints.

\section{Situation (2):}

- $\quad$ All of the students made use of the direct strategy with the following numbers and percentages: 30 students used the negative imperative construction with the high percentage of $60 \%$, and the rest, that is 20 students, used the performative scoring $40 \%$.

\section{Situation (3):}

- A large number of students, more specifically 27 students, employed the indirect conventionalized strategy via the interrogative construction scoring $42 \%$, while 23 of them used the direct strategy with 15 students employing the declarative constructionscoring $30 \%$ and 8 students employing the imperative were on the score of $16 \%$.

\section{Situation (4):}

- A high percentage was scored by the direct strategy using the imperative construction to score $60 \%$ and the performative $40 \%$. The indirect conventionalized and indirect non-conventionalized strategies scored no percentage whatsoever.

\section{Situation (5)}

- The number and percentage of the students' responses to the situations they were given could be distributed between the direct and indirect conventionalized strategies: 15 students used the imperative with the following percentage $30 \%$ and 15 students used the performative with the percentage of $30 \%$, whereas 12 students used the declarative with "can/could/might" to score $24 \%, 8$ students used the interrogative scoring $16 \%$, and 2 students used the conditional with "if I were you" to end up with $4 \%$ as a low percentage.

\section{Situation (6):}

- $\quad$ All of the students made use of the direct strategy: 33 of them used the negative imperative with the high percentage of $66 \%$ and 17 of them used the performative to score $34 \%$. The two other strategies scored no percentage in the least.

\section{Situation (7):}

- Few deployed the indirect conventionalized strategy: 15 students made use of the interrogative constructions to mark the percentage of $30 \%$ and 7 students used the declarative with "might and could" scoring $14 \%$. All the other students resorted to the direct strategy: 17 students made use of the imperative with the percentage of $34 \%$, while 20 students made use of the performative with the percentage of $40 \%$.

\section{Situation (8):}

- Equal use was made of the direct and indirect conventionalized strategies: 25 students sought to use the direct one accompanying the performative scoring $20 \%$, the negative imperative $24 \%$, and the declarative with "ought to" $4 \%$, whereas 25 students went to use the indirect conventionalized strategy with the interrogative "why don't you" scoring 50\%.

The foregoing results can be summarized in the following tables which show the frequencies of the strategies and constructions that demonstrate them. It should be taken into consideration that no table demonstrates the frequencies of the indirect non-conventionalized strategy because it has not been utilized by the subjects undertaking the test. 
Table 1. Frequencies of the direct strategy

\begin{tabular}{lllll}
\hline Situation & $\begin{array}{l}\text { Direct strategy } \\
\text { Imperative }\end{array}$ & Negative imperative & Performative & Declarative with must/should/ought to \\
\hline Situation 1 & $38 \%$ & ---- & $42 \%$ & ---- \\
Situation 2 & $60 \%$ & ---- & $40 \%$ & --- \\
Situation 3 & ---- & --- & $16 \%$ & $30 \%$ \\
Situation 4 & $60 \%$ & ---- & 40 & ---- \\
Situation 5 & $30 \%$ & ---- & $30 \%$ & $24 \%$ \\
Situation 6 & ---- & $66 \%$ & $34 \%$ & ---- \\
Situation 7 & $34 \%$ & ---- & $40 \%$ & --- \\
Situation 8 & ---- & $24 \%$ & $20 \%$ & $4 \%$ \\
\hline
\end{tabular}

Table 2. Frequencies of the indirect conventionalized strategy

\begin{tabular}{|c|c|c|c|c|}
\hline \multirow[t]{2}{*}{ Situation } & \multicolumn{4}{|c|}{ Indirect conventionalized strategy } \\
\hline & Interrogative forms & Declarative with can/could/might & Probability & Conditional \\
\hline Situation 1 & $8 \%$ & $12 \%$ & ---- & ---- \\
\hline Situation 2 & ---- & ---- & ---- & ---- \\
\hline Situation 3 & $42 \%$ & ---- & ---- & ---- \\
\hline Situation 4 & ---- & --- & --- & ---- \\
\hline Situation 5 & $16 \%$ & $24 \%$ & ---- & $4 \%$ \\
\hline Situation 6 & ---- & ---- & ---- & ---- \\
\hline Situation 7 & $30 \%$ & $14 \%$ & --- & --- \\
\hline Situation 8 & $50 \%$ & ---- & ---- & ---- \\
\hline
\end{tabular}

The tables above show the total percentage of each syntactic formula and hence the total percentage of each strategy used to formulate the speech act of advice. The table elucidates that the direct strategy scores the highest percentage, the indirect conventionalized strategy comes next, while the indirect non-conventionalized strategy scores no percentage at all. To state the results more accurately, the concatenation of the syntactic constructions should be illuminated in the manner described hereafter: as regards the direct strategy, the imperative construction won the highest percentage, followed by the performative, the negative imperative, the declarative with ought to/should/must, and, finally, the conditional with "if I were you". With respect to the indirect conventionalized strategy, the interrogative constructions, notably with "why don't you" scored the highest percentage and then comes the declarative constructions with can/could/might.

Over and above, the results of the test showed that Iraqi EFL learners, particularly males, are unaware of the social variable of status. They mostly used the speech act of advice unmitigated (i.e., without downtoners such as just, possibly, and perhaps; committers such as I think/believe, in my opinion; etc.). They were given four situations out of eight in which they are asked to advise someone with a higher status than theirs, but most of them, especially males, paid little attention to this factor. This might reflect the preference for direct strategies in Arabic. Here lies the cultural difference between Arabic and English wherein the former language prefers direct strategies, while the latter prefers indirect ones. Directness may be labelled" rude" by English native speakers. Transforming the rules and the cultural norms of the first language to the target language results in pragma linguistic failure. The absence of the conscious or unconscious knowledge of the intended meaning and the cultural norms of the target language results in miscommunication and misunderstanding (Chen, 2010). Yet, this does not mean that Arabic is less polite than English. Really, each language prefers certain conventions of politeness. To go beyond description and try to explain, Arabs tend to use direct strategies without rancor and without the intention to cause offence. This is because Arabic languageis more oriented towards positive politeness where the notions of solidarity, informality and familiarity are more valued. Directness can be considered as a marker of closeness and affiliation in Arabic (Abed, 2011). Culturally speaking, Iraqi Arabic is a collectivistic culture that favors group identity over individual autonomy. As a consequence, directness can be seen as an example of solidarity or positive politeness. That is to say, they express reciprocity, camaraderie, social closeness and common point of view when performing speech acts (ibid.). As is said earlier, linguistic politeness is culturally determined. In the diverse cultural and linguistic settings, pragmatic strategies cannot be granted as chosen from a. pre-determined ware house (Cogo \& Dewey, 2012, p. 114). Really, nonnative speakers draw on the varied resources of their linguacultural repertoires (ibid). They are skillful in exploiting the multi linguistic resources available to them. (Anchimbe, 2010). That is why conflicts occur when the people of two different cultures try to communicate with each other without knowing the appropriate methods and techniques 
of different face-threatening acts. In order to make the learners pragmatically competent, they must be aware of the socio cultural constraints of the speech acts of the target language so as to escape severe breakdowns in interethnic communication (Al-Marrani \& Sazalie, 2010).

As far as the second question about suggestion situations is concerned, the following results have been reached at:

\section{Situation (1):}

- All of the students employed the direct strategy with the performative verb "I suggest" and the noun of suggestion "my suggestion". Thus, the direct strategy ends up with $100 \%$.

\section{Situation (2):}

- The number and percentage of the strategies used is shared by the direct strategy with a performative verb or noun of suggestion $(31,62 \%)$ and the indirect conventionalized strategy that accompanies "let's" $(19,38 \%)$.

\section{Situation (3):}

- The use of the strategies varies with the direct, the indirect conventionalized, and the indirect non-conventionalized ones. The percentage of employing these structuresis as follows: the negative imperative scores $(22,42 \%)$, the performative scores $(10,22 \%)$, the interrogative constructions score $(8,16 \%)$, the impersonal constructions with "A good idea would be" and "It might be better not to" score (5, 10\%), and the conditional construction with "If I were you" scores $(5,10 \%)$.

\section{Situation (4):}

- The direct strategy got the highest percentage. More specifically, the performative scored (29, 58\%), whereas the imperative scored $(7,14 \%)$. The indirect conventionalized strategy comes next, but, this time, the constructions indicating possibility/probability score the highest percentage $(11,22 \%)$, while the conditional construction scores only $(3,6 \%)$.

\section{Situation (5):}

- The indirect conventionalized strategy using "let's" scored the highest percentage, that is $(35,70 \%)$, followed by the interrogative constructions $(15,30 \%)$. Hence, the indirect conventionalized strategy scored $100 \%$.

\section{Situation (6):}

- The distribution of scoring varies with the direct and indirect conventionalized strategies in the manner described hereafter: as far as the direct strategy is concerned, the imperative and the performative score the highest percentages, that is $(15,30 \%)$ and $(17,34 \%)$ respectively, while the indirect strategy, the interrogative constructions scored $(5,10 \%)$, the constructions denoting possibility/probability score $(8,16 \%)$, and the conditional "If I were you" scores $(5,10 \%)$.

\section{Situation (7):}

- $\quad$ The students as a whole employed the direct strategy with the imperative construction scoring $(19,38 \%)$ and the performative with a noun or a verb scoring $(31,62 \%)$.

\section{Situation (8):}

- The number and percentage of scoring varies with the different types of strategies: the imperative scores (7, $14 \%)$, the performative $(8,16 \%)$, the interrogative $(10,20 \%)$, the constructions with possibility/probability (10, $20 \%)$, the conditional $(4,8 \%)$, and the impersonal constructions $(11,22 \%)$.

The following tables summarize the frequencies of the strategies and the constructions used to denote them in each situation: 
Table 3. Frequencies of the direct strategy

\begin{tabular}{llll}
\hline Situation & $\begin{array}{l}\text { Direct strategy } \\
\text { Imperative }\end{array}$ & Negative imperative & Performative \\
Situation 1 & ---- & --- & $100 \%$ \\
Situation 2 & ---- & --- & $62 \%$ \\
Situation 3 & & $42 \%$ & $22 \%$ \\
Situation 4 & $14 \%$ & & $58 \%$ \\
Situation 5 & ---- & --- & ---- \\
Situation 6 & $30 \%$ & --- & $34 \%$ \\
Situation 7 & $38 \%$ & ---- & $62 \%$ \\
Situation 8 & $14 \%$ & ---- & $16 \%$ \\
\hline
\end{tabular}

Table 4. Frequencies of the indirect conventionalized strategy

\begin{tabular}{|c|c|c|c|c|}
\hline \multirow[t]{2}{*}{ Situation } & \multicolumn{4}{|c|}{ Indirect conventionalized strategy } \\
\hline & Interrogative forms & Let's & Possibility/probability & Conditional \\
\hline Situation 1 & ---- & $\begin{array}{l}--- \\
-\end{array}$ & --- & ---- \\
\hline Situation 2 & $16 \%$ & ---- & ---- & $10 \%$ \\
\hline Situation 3 & $16 \%$ & --- & --- & $10 \%$ \\
\hline Situation 4 & ---- & ---- & $22 \%$ & $6 \%$ \\
\hline Situation 5 & $30 \%$ & $70 \%$ & ---- & ---- \\
\hline Situation 6 & $10 \%$ & ---- & $16 \%$ & $10 \%$ \\
\hline Situation 7 & --- & --- & --- & --- \\
\hline Situation 8 & $20 \%$ & ---- & $20 \%$ & $8 \%$ \\
\hline
\end{tabular}

Table 5. Frequencies of the indirect non-conventionalized strategy

\begin{tabular}{lll}
\hline Situation & $\begin{array}{l}\text { Indirect non-conventionalized strategy } \\
\text { Impersonal constructions }\end{array}$ & Hints \\
\hline Situation 1 & ---- & ---- \\
Situation 2 & ---- & ---- \\
Situation 3 & $10 \%$ & --- \\
Situation 4 & ---- & ---- \\
Situation 5 & ---- & ---- \\
Situation 6 & --- & ---- \\
Situation 7 & --- & ---- \\
Situation 8 & $22 \%$ & ---- \\
\hline
\end{tabular}

The foregoing tables display the total percentage of each syntactic formula. The tables illuminate that the direct strategy scores the highest percentage; the indirect conventionalized strategy comes next. They also demonstrate that there is an apparent paucity in the use of the indirect non-conventionalized strategy. To state the results more accurately, the gradation of each syntactic construction should be examined as follows: with regard to the direct strategy, the performative construction, whether with a performative verb or a noun of suggestion won the highest percentage, followed by the imperative, and the negative imperative. With respect to the indirect conventionalized strategy, the interrogative constructions scored the highest percentage and then came the construction with "let's", the conditional and the construction with possibility/probability. Concerning the indirect non-conventionalized strategy, there is an obvious shortage in its use. More specifically, the impersonal constructions scored a limited percentage if compared with other constructions; whereas hints were evidently absent in students' responses to the situations they were given. Students obviated the use of hints because they preferred being direct whereas in making hints there is no indicator of the intended force of the utterance. Moreover, the hearer will be left inferring what the speaker intends his utterance to count as.

Again, the results of the test showed that most Iraqi EFL learners, particularly males, are unaware of "status" as a social variable. They mostly used the speech act of suggestion. They were given four situations out of eight in which they were asked to give suggestions to someone with a higher status than theirs, but most of them, especially males, averted this factor. This might reflect the preference for direct strategies in Arabic. This goes in line with what has been stated by Koester (2002, p. 181) about directness in English where he mentioned that directness in suggesting is not widely employed in everyday interaction in English.

Iraqi EFL learners have many problems in their attempt to match their performance with that of the native choice 
concerning the appropriate strategy. They showed less preference for the strategy used by English native speakers. Instead they resorted to their native language (Arabic) by transferring its norms and applying them to the target language, i.e., English. When the native speakers violate speech act realization pattern typically used by native speakers of a target language, they often suffer the perennial risk of inadvertently violating conversational and politeness norms thereby forfeiting their claims to being treated by their interact ants as social equals (Phuong, 2006). Really, lack of pragmatic competence in the target language may indicate that the learner is impolite (Jiang, 2006).

Yet, this failure of adhering to the target language norms can be attributed to cultural differences. Iraqi EFL learners of English tend to be direct as they are influenced by their Iraqi Arabic. They want to be explicit in their suggestion and advice by being direct. In Iraqi culture making speech acts is regarded as rapport-building strategy that can be seen as a token of solidarity. In society with collectivism value system like Iraq, the group harmony is valued to a great extent. Here, making suggestion and giving advice is a way of keeping interpersonal relationships harmonious, while in individualistic society like English, individual autonomy and personal territory are sensitive and people are not allowed to intrude (Hofstede, 1991; Abed, 2011) Unlike in the west, directness in the Arabic culture, as mentioned by Aribi (2011), is linked with positive cultural values like sincerity, straightforwardness and cordiality rather than imposition on people's freedom of action. As such, Iraqi EFL learners, in general, employ high levels of directness without the fear of losing the "face" because they are influenced by their Iraqi cultural background and traditions according to which they may resort to directness which is the expected behavior in Iraqi social context.

\section{Pedagogical Implications}

EFL learners are required to consider options and select among alternatives to produce contextually appropriate speech acts. Failure to adhere to appropriateness may lead to unintended consequences and unequal treatment of the learner .Culturally appropriate choices when interacting with different groups will potentially lead to more positive experience, increased motivation, and appealing outcomes for the learners (Kasper \& Rose, 2002). Based on this line of thinking, learners need to understand the ramification of utilizing different linguistic options in certain situations and contexts. It is important for the learners to be conscious of their options and the consequences that result from appropriate and inappropriate choices.

In this regard, the focus of classroom instruction on grammatical and discourse rules of a target language may lead learners to pragmatic errors and therefore to miscommunication. Studies on interlanguage pragmatics have shown that second or foreign language learners and even advanced language learners are likely to make serious communicative errors which lead to failure in expressing and understanding the intended value of the utterances (Delahaie, 2011).

$\mathrm{Yu}(2005)$ asserts that in addition to the knowledge of structures and discourse rules, foreign language learners should pay heed to the sociolinguistic and pragmatic rules of the target language when they talk to native speakers. By not doing so, these learners seem so improper or incompetent to the point that this may engender cross cultural misunderstanding and offence. Therefore, language teachers need to incorporate cross-cultural differences in their instruction syllabus.

Iraqi Teachers and syllabus designers per se have to integrate socio-pragmatic components in their programs of teaching English language if they want their learners to succeed in speaking and using English appropriately when interacting with native speakers of English. Hence, learners should be aware of the socio-cultural and pragmatic differences between Arabic and English. They should be taught that "indirectness" is highly valued in Anglo-Saxon societies and being "direct" with native speakers of English may cause misunderstanding. The teaching of speech acts in this regard should be based on a whole range of strategies available to learners so as to widen the input they receive .Learners need to be exposed to the way speech acts are used in foreign language instructional contexts in order to avoid social misunderstanding .In fact, foreign language learners, in general, need to understand culture, context and politeness to be able to function and communicate properly in the target language. Teachers could help learners understand appropriate politeness in communication by presenting the preferred and dispreferred strategies in the form of discussion or debate in relation to target language structures. The exposure of EFL learners to authentic materials can highly benefit them to raise their awareness about pragmatic issues such as politeness (Kasper \& Roever, 2005).

\section{Final Remarks}

Studies on speech acts in various languages and contexts could help bridge the gap among the speakers of different languages, i.e. help to alert and inform those speakers of the potential pragmatic failure that may arise in social and pedagogical domains. These studies may also help speakers of dissimilar languages and cultures 
cope with interethnic communication difficulties .For this reason, the study of speech acts reveals a great deal of information about language users and their societies. Byon (2006, p. 137) claims that "speech acts reflect the fundamental values and social norms of target language and demonstrate the rules of language use in a speech community."

Iraqi EFL learners perform direct strategies better than the indirect ones. That is why understanding and producing speech acts is thought to be an indispensable constituent of language learners' grammatical and social knowledge about learning a language and using the utterances appropriately in the target language. As such, Bella (2011) argues that deviation from the target norms due to cultural differences may have debilitating effects on the learners' language proficiency. Bayat (2013) mentions that though speech acts appear to be universal, their conceptualization can vary to a great extent across cultures.

Iraqi EFL learners have displayed a pragmalinguistic deficiency because they use more direct strategies in performing speech acts which call for conventional indirectness. The conventional indirectness is the most proper form which must be skillfully taught to EFL learners because direct strategies may imply disregard to face and non-conventional indirectness conveys regard to pragmatic opacity (ibid). However, as has been stated earlier, Iraqi EFL learners' directness could be related to the notion of the positive face. Iraq is a collectivistic society that focuses on the positive politeness orientation and values - in group nexus, solidarity, and esteem.

Finally, it has been noticed that unlike their male mates, Iraqi EFL female learners are more aware of the social variable of status when giving advice and suggestions. They are successful in manipulating downtoners, softeners, and committers to lessen the impact of the two speech acts which are considered face threatening acts when issued by a person with a lower status to someone with a higher status. This is because females have a propensity to maintain status. Unlike males, they are status sensitive and are closer to prestige. They are skillful in selecting linguistic forms which express appropriate degree of social distance or which recognize relevant status or power differences.

\section{References}

Abed, A. Q. (2011). Pragmatic Transfer in Iraqi EFL Learners' Refusal. International Journal of English Linguistics, 1(2). https://doi.org/10.5539/ijel.v1n2p166

Al-Maramani, Y., \& Sazalie, A. (2010). Polite Requests Strategies by Yemini Females: A Sociopragmatic Study. MJAL-2.478-516.

Anchimbe, E. A. (2010). Local or International Standards: Indigenized varieties of English at the Crossroads. In F. Sharifian (Ed.), English as an International Language: Perspectives and Pedagogical Issues. Bristol: Mulitilingual Matters.

Aribi, I. (2011). Requests in Strategies as used by Tunsian ESP learners. Unpublised M.A. Thesis, Tunsian Faculty of Letters and Humanities. Sfax, Tunsia.

Austin, J. L. (1962). How to Do Things with Words. Oxford: Oxford University Press.

Bayat, N. (2013). A Study on the Use of Speech Acts. Procedia: Social and Behavioural Sciences, 70, 213-221. https://doi.org/10.1016/j.sbspro.2013.01.057

Bella, S. (2011). Mitigation and Politeness in Greek Invitation Refusals: Effects on Length of Residence in the target Community and Intensity of Interaction on Non-Native speakers' Performance. Journal of Pragmatics, 43(6), 1718-1740. https://doi.org/10.1016/j.pragma.2010.11.005

Boumeester, O. (2010). Economic Adviceand Rhetoric: Why do Consultants Perform better than Academic Advisors? Massachusetts: Edward Elgar Publishing. https://doi.org/10.4337/9781849805117

Brown, P., \& Levinson, S. (1987). Politeness: Some Universals in Language Usage. Cambridge: Cambridge University Press.

Byon, A. S. (2006). Apologizing in Korean: Cross- cultural Analysis in Classroom Settings. Korean Studies, 29(2), 137-166

Chen, P. (2010). On Pragmatic Strategies for Avoidance of Explicitness in Language. Asian Social Sciences, 6(10). https://doi.org/10.5539/ass.v6n10p147

Cogo, A., \& Dewey, M. (2012). Analyzing English as a Lingua Franca. London: Continuum International Publishing Group.

Delahaie, J. (2011). Sociopragmatic Competence in EFL Language Teaching: Discourse Markers as Contextual Cues. Bristol: Meaning \& Context. 
Hinkel, E. (1994). Appropriateness of Advice as L2 Solidarity Strategy. RELC Journal, 25. https://doi.org/10.1177/003368829402500205

Hofstede, G. (1991). Culture and Organizations: Software of the Mind. London: McGraw-Hill.

Jiang, X. (2006). Suggestions: What should ESL Students Know? System, 34(1), 36-54. https://doi.org/10.1016/j.system.2005.02.003

Kasper, G., \& Roever, C. (2005). Pragmatics in Second Language learning. In E. Hinkel (Ed.), Handbook of Research in Second Language Teaching and Learning. NewJersey: Eribaum Associates.

Koester, A. J. (2002). The Performance of Speech Acts in Workplace Conversations and the Teaching of Communicative Functions. System, 30. https://doi.org/10.1016/S0346-251X(02)00003-9

Koike, D. A. (1996). Transfer of Pragmatic Competence and Suggestions in Spanish Foreign Language Learning. In S. M. Grass \& J. Neu (Eds.), Speech Acts cross Cultures. Berlin: Mouton De Gruyter.

Lakoff, R. T., \& Ide, S. (Eds.) (2005). Broadening the Horizon of Linguistic Politeness. Amesterdam: John Benjamins Publishing Company. https://doi.org/10.1075/pbns.139

Leech, G., \& Svartvik, J. (1996). A Communicative Grammar of English. New York: Longman Publishing.

Martinez-Flor, A. (2003). Non-Native Speakers' Production of Advice Acts: The Effects of Proficiency (pp. 139-153). Castellon: University Jaume I.

Martinez-Flor, A. (2005). Theoretical Review of the Speech Act of suggesting: Towards a Taxonomy for its Use in FLT (pp. 167-187). Revista Alicantina De Studios Ingleses, No18. Castellon: University Jaume I.

Matsumura, S. (2001). Learning the Rules for Offering Advice. A Quantitative Approach to Second Language Socialization. Language Learning. https://doi.org/10.1111/0023-8333.00170

Nakagawa, J., \& Nishimura, T. (1998). Cross Over: Communicative Writing Skills. Tokyo: Sansyusha.

Phuong, T. M. (2006). Crosscultural Pragmatics: Refusal and the Requests by Austerlian Native Speakers of English and Vietnamese Learners of English. M.A. Dissertation. The University of Queensland, Austerlia.

Searle, J. R. (1969). Speech Acts: An Essay in the Philosophy of Language. Cambridge: Cambridge University Press. https://doi.org/10.1017/CBO9781139173438

Thomas, J. (1995). Meaning in Interaction: An Introduction to Pragmatics. New York: Longman.

Thomson, A. J., \& Martinet, A. V. (2001). A Practical English Grammar. Oxford: Oxford University Press.

Yu, M. C. (2005). Sociolinguistic Competence in Complimenting Act of native Chinese and American English Speakers: A mirror of cultural value. Language and Speech, 48(1), 91-119. https://doi.org/10.1177/00238309050480010501

\section{Copyrights}

Copyright for this article is retained by the author(s), with first publication rights granted to the journal.

This is an open-access article distributed under the terms and conditions of the Creative Commons Attribution license (http://creativecommons.org/licenses/by/4.0/). 